\title{
Identification of phthalates in stem cell donors
}

\author{
Svenja Degenhardt ${ }^{\mathrm{a}}$, Olga Janz ${ }^{\mathrm{a}}$, Mirjana Slijepcevic ${ }^{\mathrm{b}}$ and F. Wenzel ${ }^{\mathrm{c}, *}$ \\ ${ }^{a}$ Medical and Life Sciences, Hochschule Furtwangen University, Germany \\ ${ }^{\mathrm{b}}$ Institute for Haemostaseology, Haemotherapy and Transfusion Medicine, University Hospital \\ Düsseldorf, Germany \\ ${ }^{\mathrm{c}}$ Hochschule Furtwangen, Campus Schwenningen, Fakultát Medical and Life Sciences, - Medizinische \\ Diagnostik, Villingen-Schwenningen, Germany
}

\begin{abstract}
Apheresis products are regularly stored in bags containing phthalates. This study was initialized to find a possible relation between storage period, storage temperature, and diverse organic and non-organic substances with the migration of phthalates out of PVC-containing medical products as bags. Data were obtained by the observation of 20 autogenic peripheral stem cell donors, 21 allogenic peripheral stem cell donors as well as 10 bone marrow donors. Identification and quantification of DEHP and MEHP (primary metabolite of DEHP) was realized due to high performance liquid chromatography-mass spectrometry (LCMS). The results revealed that DEHP diffused out of the tube system (as part of apheresis device) into the blood and was then also detectable in apheresis products. Further experiments focused on storage conditions could demonstrate that migration of DEHP out of PVC-containing storage bags directly correlated with storage temperature. In addition, concentrations of DEHP and MEHP were also influenced by storage period. All concentrations of DEHP remained below the recommended "tolerable daily intake" (TDI).
\end{abstract}

Keywords: Di(2-ethylhexyl) phthalate, DEHP, MEHP, stem cell apheresis, storage conditions, PVC

\section{Introduction}

Di(2-ethylhexyl) phthalate (DEHP) is a plasticizer used in medical products made with polyvinyl chloride (PVC) plastic. More than 2.7 tons of phthalates are produced synthetically each year. Within this group, DEHP is the most produced phthalate and represents nearly $40 \%$ of the PVC production $[29,30]$.

DEHP is highly lipophilic and hydrophobic [1]. Dissolution of DEHP out of the material can have positive effects for erythrocyte concentrates. It could be shown that DEHP is able to protect membranes of erythrocytes and as a result flow rates of erythrocytes and blood remain intact. Another effect is the reduction of osmotic fragility and in that respect increase of osmotic resistance [2]. Samson reported that there is up to 50\% more hemolysis observed in DEHP-free blood bags and another study also found an increased number of erythrocytes in bags containing DEHP (24 $\mathrm{h}$ after transfusion) [3-5]. These effects cannot be linked to Monoethylhexylphthalat (MEHP), a primary metabolite of DEHP [6]. Furthermore, the concentration of DEHP in the blood, which is stored in PVC bags, is directly proportional to temperature and time of storage [7]. Due to permanent migration of DEHP,

\footnotetext{
*Corresponding author: Dr. med. habil. F. Wenzel, Hochschule Furtwangen, Campus Schwenningen, Fakultát Medical and Life Sciences, - Medizinische Diagnostik, Jakob-Kienzle-Str. 17, 78054 Villingen-Schwenningen, Germany. Tel.: +497720 307 4358; E-mail: folker.wenzel@gmx.de.
} 
the material becomes brittle and the surface structure alters. Cole et al. were able to show that frozen plasma contained significantly less DEHP and MEHP than non-frozen plasma which was exposed to summerlike temperatures [8]. The diffusion property of DEHP is also used for sports drug screening. Therefore, detection of DEHP and its metabolites which derive from tube systems and blood bags can provide evidence of cumulative autologous (detection of extrinsic blood system antigens is not possible) and allogenic blood transfusions $[9,10]$.

DEHP has a low acute toxicity level, but has been shown to produce a wide range of adverse effects in experimental animals. However, there is evidence that DEHP may also cause adverse reproductive effects in humans $[1,4,11]$.

This study focused on DEHP as one of the most widely-used phthalates along with its primary metabolite MEHP and how they might have effects on allogenic and autologous stem cell apheresis products.

\section{Material and methods}

\subsection{Donors}

This study is based on data derived from 51 stemm cell donations. The community was composed of 20 autogenic peripheral stem cell donors, 21 allogenic peripheral stem cell donors and 10 bone marrow donors, all groups consisting of both males and females.

Following parameters were collected: sex, age (years), weight $(\mathrm{kg})$, size $(\mathrm{cm})$, blood volume $(\mathrm{ml})$, leucocyte count per $\mu \mathrm{l}$, red blood cell count $(\mathrm{M} / \mu \mathrm{l})$, thrombocyte count per $\mu \mathrm{l}$, hemoglobin $(\mathrm{g} / \mathrm{dl})$, creatinine in serum $(\mathrm{mg} / \mathrm{dl})$ and glomerular filtration rate $(\mathrm{ml} / \mathrm{min})$ in average.

\subsection{Stem cell apheresis}

Apheresis was performed, after stem cells were mobilized out of the bone marrow into peripheral blood stream. A Cobe Sprectra apheresis system (Cobe Spectra I, II, II or IV, software version 4.7 or 6.1 PBSC, Gambro BCT) was used along with the corresponding apheresis kit (CobeSpectra Closed Blood Cell Set, FC “WBC” ISBT, Gambro BCT) to collect patients' blood via peripheral access (or central venous catheter). The blood was anticoagulated and directed into the apheresis system. Anticoagulants were ACD-A and Heparin (unfractionated Heparin, Heparin-Natrium-5000-ratiopharm, Ratiopharm). $5 \mathrm{ml} \mathrm{ACD}-\mathrm{A}$ and Heparin were directed to the collecting bag via the tubes of the system and then stem cells were collected. In addition to, aliquots of each collecting bag were taken after apheresis under sterile conditions.

\subsection{Flow cytometry}

Cell analysis was conducted on a Beckman Coulter Epics XL MCL flow cytometer with a corresponding software (EXPO 32/RXP). Here, an argon-ion laser (488 nm) was used.

\subsection{Sample preparation for chromatography}

HPLC-MS/MS was used to detect DEHP and MEHP in plasma and apheresis samples. Aliquots of $50 \mu \mathrm{l}$ were mixed with $5 \mu \mathrm{l}$ of internal standard of $50 \mathrm{ng} / \mathrm{ml}$ concentration and protein precipitation was made with acetonitrile (VWR International GmbH, Darmstadt, Germany) in 2.5-fold excess. After 5 minutes of centrifugation at $17000 \mathrm{G}$ (Heraeus Pico17 Centrifuge, Thermo Scientific, Dreieich, 
Germany), the supernatants were transferred to glass vials and subsequently analyzed. Quantification was realized due to a calibration line with at least 6 calibration points of a concentration range between 0 and $100 \mu \mathrm{g} / \mathrm{ml}$. Reference materials for this procedure were DEHP and MEHP (Camebridge Isotope Laboratories Inc., Andover, MA, USA) diluted in deionized water (Sartorius Stedim Biotech S.A., Aubagne, France). Internal standards were stable isotype-labelled analogues: D4-DEHP and ${ }^{13} \mathrm{C} 4-$ MEHP (Camebridge Isotope Laboratories Inc., Andover, MA, USA).

Chromatography is performed on an Agilent 1100 series HPLC (Agilent Technologies, Waldbronn, Germany) connected over a HESI-source with a 4000-Q-Trap mass spectrometer (Applied Biosystems, Darmstadt, Germany).

For the LC-System a Nucleodur- $\mathrm{C}_{18}$-column $(50 \times 2,1 \mathrm{~mm}, 3 \mu \mathrm{m}$ particle size $)$ was used. Solvents were $5 \mathrm{mM}$ ammonium-acetate (solvent A) and acetonitrole (solvent B) and the start point of the gradient was $10 \% \mathrm{~B}$ which was evenly raised to $100 \%$ within 8 minutes. The procedure was continued with an isocratic elution with $100 \% \mathrm{~B}$ for 3 minutes. To re-equilibrate the column the initial solvent composition was driven for further 4 minutes at a flow rate of $250 \mu \mathrm{l} / \mathrm{min}$ and an injection volume of $10 \mu 1$.

\section{Results}

\subsection{Blood counts from peripheral blood}

To first get an overview of the data, the blood counts of autologous and allogenic stem cell donors were compared. The focus laid on the number of blood cells, kidney parameter creatinine and the glomerular filtration rate with the aim to determine whether there can a significant difference in the cell count of peripheral blood being observed between those groups.

Means and standard deviations of blood counts of peripheral blood from allogenic and autologous stem cell donors before and after apheresis are outlined in Table 1. Data show that in mean the numbers of all blood cell types were higher before the apheresis procedure for both groups than after. Autologous stem cell donors showed significant lower values for all analyzed blood parameters compared to allogenic donors $\left(p<0,05\right.$, student's $t$-test). $\mathrm{CD} 34^{+}$cell numbers were only detected before apheresis for both groups, but the absolute number of $\mathrm{CD}_{3} 4^{+}$cells was significantly higher for autologous stem cell donors ( $p<0,05$, student's $t$-test). In contrast, a significant increase in numbers of leukocytes, thrombocytes, hemoglobin concentration and hematocrit could be observed for allogenic stem cell donors when compared to the autologous group.

\subsection{Detection of DEHP and MEHP from peripheral blood}

Blood samples from allogenic and autologous donors were analyzed to obtain data regarding contents of phthalates DEHP and MEHP.

Table 2 summarizes means and standard deviations of MEHP and DEHP for allogenic and autologous stem cell donors before and after apheresis. The value determined in average for DEHP from allogenic stem cell donors before apheresis procedure was below the detection limit. After apheresis the value did not increase significantly to a mean of $0.09 \mu \mathrm{g} / \mathrm{ml} \pm 0.19(p>0.05$, student's $t$-test). For autologous donors mean value of DEHP was $0.22 \mu \mathrm{g} / \mathrm{ml} \pm 0.17$ before apheresis and increased significantly to a mean of $0.88 \mu \mathrm{g} / \mathrm{ml} \pm 0.42$ after apheresis $(p<0,05$, student's $t$-test).

Furthermore, the mean value of MEHP was below the detection limit for allogenic donors before apheresis and was not significant higher after apheresis (mean $0,12 \mu \mathrm{g} / \mathrm{ml} \pm 0,06, p>0,05$, student's $t$-test). Therefore, MEHP could not be detected in samples from autologous donors. 


\subsection{Detection of DEHP and MEHP from apheresis products}

Apheresis products from autologous stem cell donors were also analyzed for DEHP and MEHP with additional focus on possible influence of storage period and storage temperature. After apheresis the products from autologous donors were immediately analyzed and detected. Mean values were $5.2 \mu \mathrm{g} / \mathrm{ml} \pm 3.3$ for DEHP and $0.29 \mu \mathrm{g} / \mathrm{ml} \pm 0.28$ for MEHP.

Apheresis products of autologous stem cell donors were additionally checked for amounts of DEHP and MEHP before re-transfusion after the bags were stored via cryopreservation and values were compared to those obtained immediately after apheresis. Storage period was in mean 47 days at $-175^{\circ} \mathrm{C}$. After storage via cryopreservation the mean value increased significantly to $7.07 \mu \mathrm{g} / \mathrm{ml} \pm 5.54$ $(p<0.05$, student's $t$-test, Fig. 1). Furthermore, MEHP showed a significantly increased mean value of $0.57 \mu \mathrm{g} / \mathrm{ml} \pm 0.59(p<0.05$, student's $t$-test, Fig. 1). For allogenic stem cell donors mean values of $0.92 \mu \mathrm{g} / \mathrm{ml} \pm 0.51$ for DEHP and $10.07 \mu \mathrm{g} / \mathrm{ml} \pm 4.40$ for MEHP were obtained for apheresis products immediately after apheresis. The mean values of both DEHP and MEHP were significantly increased in apheresis products from allogenic donors, when means of DEHP and MEHP from autologous and allogenic donors were compared ( $p<0.05$, student's $t$-test, Fig. 2).

Table 1

Blood counts from peripheral blood of allogenic and autologous donors

\begin{tabular}{lccccc}
\hline & \multicolumn{2}{c}{ Allogenic donors } & & \multicolumn{2}{c}{ Autologous donors } \\
\cline { 2 - 3 } & before PBSC & after PBSC & & before PBSC & after PBSC \\
\hline Leukocytes $(\mathrm{K} / \mu \mathrm{l})$ & 44,3 & 41,4 & & 23,8 & 19 \\
Leukocytes $(\mathrm{K} / \mu \mathrm{l}) \mathrm{SD}$ & 13,2 & 13,3 & & 16,9 & 14,4 \\
$\mathrm{Hb}(\mathrm{g} / \mathrm{dl})$ & 14,2 & 13,5 & & 9,9 & 9,1 \\
$\mathrm{Hb}(\mathrm{g} / \mathrm{dl}) \mathrm{SD}$ & 0,6 & 0,7 & & 1,1 & 1 \\
$\mathrm{Hct}(\%)$ & 43 & 41 & & 30 & 28 \\
$\mathrm{Hct}(\%) \mathrm{SD}$ & 1,9 & 2 & & 3,5 & 3 \\
Erythrocytes $(\mathrm{M} / \mu \mathrm{l})$ & 7,9 & 4,7 & & 3,4 & 3,1 \\
Erythrocytes $(\mathrm{M} / \mu \mathrm{l}) \mathrm{SD}$ & 0,2 & 0,3 & & 0,4 & 0,4 \\
Thrombocytes $(\mathrm{K} / \mu \mathrm{l})$ & 242 & 132 & & 121 & 72 \\
Thrombocytes $(\mathrm{K} / \mu \mathrm{l}) \mathrm{SD}$ & 58,8 & 38,8 & & 99,3 & 47,9 \\
$\mathrm{CD} 34^{+}\left(10^{6} / \mathrm{kg} \mathrm{bw}\right)$ & 2,59 & & & 3,57 & \\
$\mathrm{CD} 34^{+}\left(10^{6} / \mathrm{kg} \mathrm{bw}\right) \mathrm{SD}$ & 0,7 & & & 2,7 & \\
\hline
\end{tabular}

Table 2

Mean values and standard derivations of MEHP and DEHP concentrations for allogenic and autologous stem cell donors

\begin{tabular}{lcccccc}
\hline & \multicolumn{2}{c}{ Allogenic donors } & & \multicolumn{2}{c}{ Autologous donors } \\
\cline { 2 - 3 } \cline { 5 - 6 } & before apheresis & after apheresis & & before apheresis & after apheresis \\
\hline MEHP $(\mu \mathrm{g} / \mathrm{ml})$ mean & 0 & 0,12 & & 0 & 0 \\
MEHP $(\mu \mathrm{g} / \mathrm{ml})$ SD & 0 & 0,06 & & 0 & 0 \\
DEHP $(\mu \mathrm{g} / \mathrm{ml})$ mean & 0 & 0,09 & & 0,22 & 0,88 \\
$\operatorname{DEHP}(\mu \mathrm{g} / \mathrm{ml})$ SD & 0 & 0,19 & & 0,17 & 0,42 \\
\hline
\end{tabular}




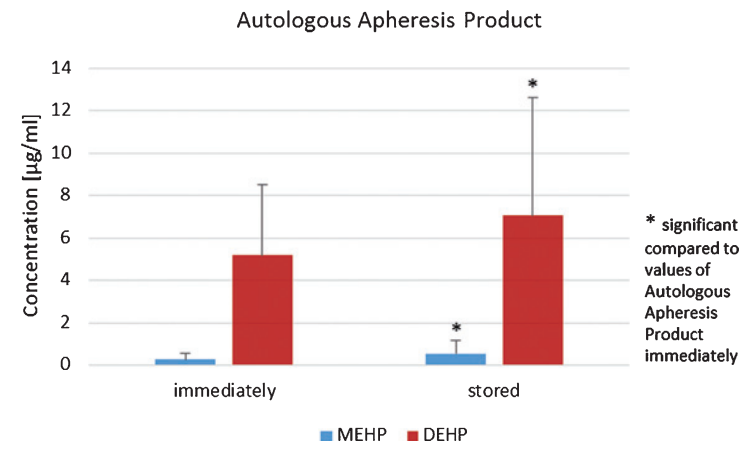

Fig. 1. DEHP and MEHP concentrations in autologous apheresis products before and after 47 days storage at $-175^{\circ} \mathrm{C}$.

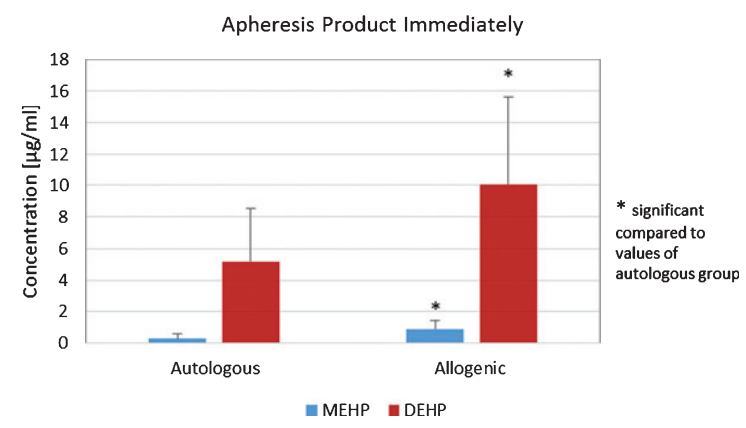

Fig. 2. Concentrations of apheresis products from allogenic donors analyzed immediately after apheresis.

\subsection{Detection of DEHP and MEHP in bone marrow preparations of allogenic bone marrow donors}

Amounts of DEHP and MEHP were also analyzed in bone marrow preparations derived from allogenic donors with additional focus on the storage period. Storage conditions were $72 \mathrm{~h}$ at $4{ }^{\circ} \mathrm{C}$ and analyses were made after $0 \mathrm{~h}, 24 \mathrm{~h}, 48 \mathrm{~h}$ and $72 \mathrm{~h}$.

Concentrations of MEHP increased during $72 \mathrm{~h}$ of storage. MEHP and DEHP were already detected in the preparation of allogenic bone marrow donors immediately after donation. Both phthalates showed a significant increase in the mean values during storage $(p<0.05$, Student's $t$-test, Fig. 3$)$.

When both groups of allogenic donors (stem cell vs. bone marrow) were compared in respect to concentrations of MEHP and DEHP the statistical test revealed that concentrations in apheresis products from allogenic stem cell donors were significant higher than in bone marrow preparations of allogenic bone marrow donors $(p<0.05$, Student's $t$-test).

\subsection{Storage of plasma, apheresis product, mixture of plasma + apheresis product from allogenic stem cell donors}

Another focus was on the amounts of MEHP and DEHP in pure plasma and pure apheresis product as well as in the mixture of plasma and apheresis product $(3: 1)$. The substances were stored at $4^{\circ} \mathrm{C}$ for $72 \mathrm{~h}$ and analyses were made after $0,24,48$ and $72 \mathrm{~h}$.

Concentrations of DEHP in plasma significantly increased during $72 \mathrm{~h}$ of storage $(p<0.05$, Student's $t$-test, Fig. 4). In addition, DEHP and MEHP in apheresis products from allogenic stem cell 


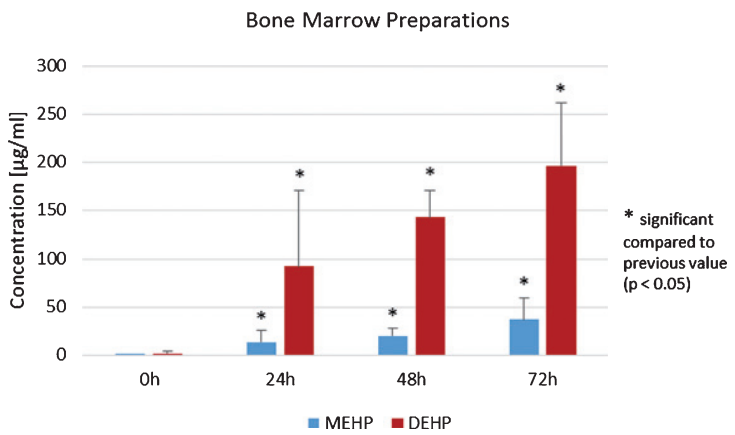

Fig. 3. Mean values of phthalates MEHP and DEHP in bone marrow preparations at storage time points $0,24,48$ and $72 \mathrm{~h}$.

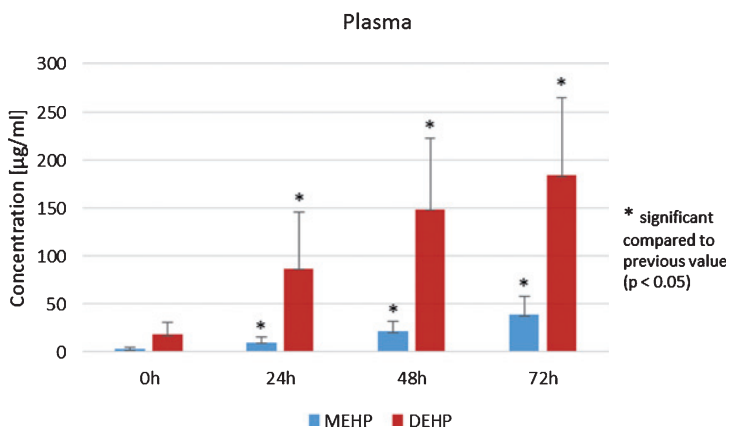

Fig. 4. Analysis of MEHP and DEHP in the plasma of allogenic peripheral stem cell donors.

donors significantly increased during the $72 \mathrm{~h}$ storage period $(p<0.05$, Student's $t$-test). Analysis of the plasma/apheresis product mixture $(3: 1)$ again showed a statistically significant increase of MEHP and DEHP during $72 \mathrm{~h}$ storage at $4{ }^{\circ} \mathrm{C}(p<0.05$, Student's $t$-test, Fig. 5$)$. Furthermore, the ratio of DEHP and MEHP in plasma, apheresis product and the mixture thereof during the $72 \mathrm{~h}$ of storage were of interest. For pure apheresis product there was no significant relationship of DEHP and MEHP detected. In contrast, pure plasma showed a significant decrease during $72 \mathrm{~h}$ storage $(p<0.05$, Student's $t$-test). After $72 \mathrm{~h}$ of storage, a significant decrease of DEHP/MEHP ratio was also detected in the mixture $(3: 1)$ of plasma and the apheresis product $(p<0.05$, Student's $t$-test).

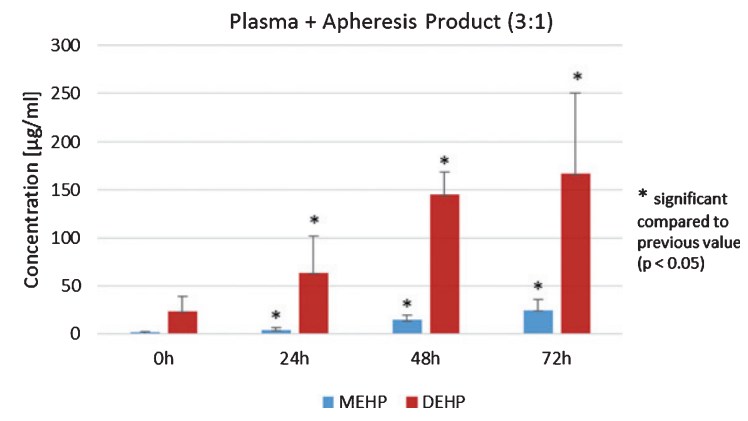

Fig. 5. Plasma/apheresis mixture (3:1) analysis of DEHP and MEHP concentrations. 


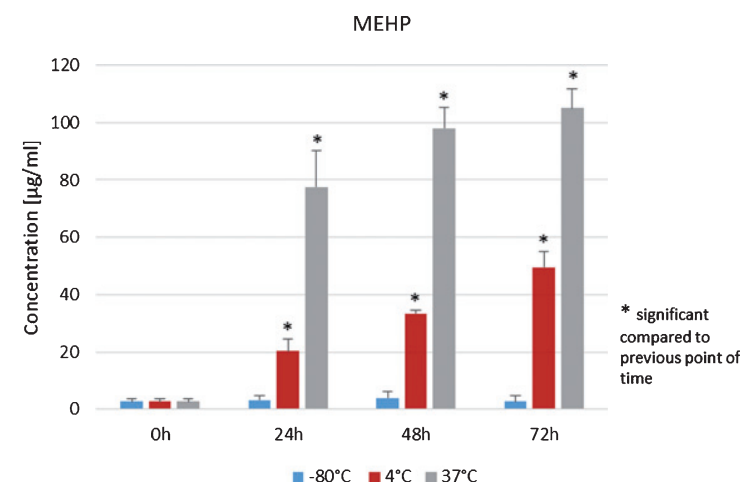

Fig. 6. MEHP concentrations in the plasma of peripheral stem cell donors during storage at $-80^{\circ} \mathrm{C}, 4^{\circ} \mathrm{C}$ and $37^{\circ} \mathrm{C}$.

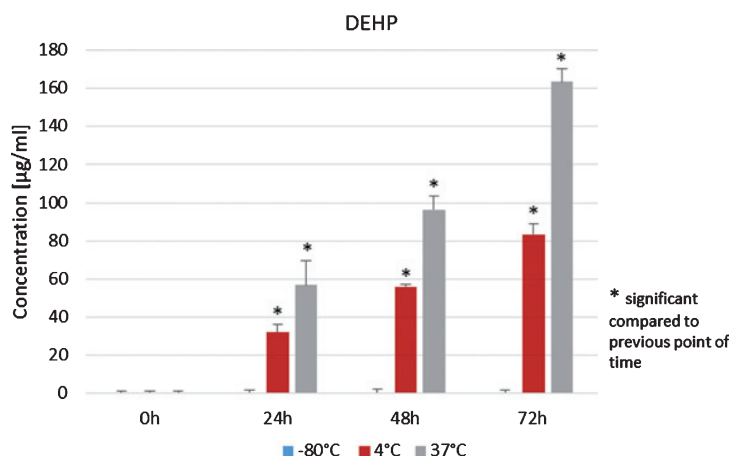

Fig. 7. DEHP concentrations in the plasma of peripheral stem cell donors during storage at $-80^{\circ} \mathrm{C}, 4^{\circ} \mathrm{C}$ and $37^{\circ} \mathrm{C}$.

\subsection{Storage of plasma from allogenic peripheral stem cell donors at $4^{\circ} \mathrm{C}, 37^{\circ} \mathrm{C}$ and $-80^{\circ} \mathrm{C}$}

To determine which influence the condition storage temperature has on concentrations of DEHP and MEHP in plasma of peripheral stem cell donors, samples were stored at $4{ }^{\circ} \mathrm{C}, 37^{\circ} \mathrm{C}$ and $-80^{\circ} \mathrm{C}$ for 72 hours. Concentrations of DEHP and MEHP were measured immediately before storage and after $24 \mathrm{~h}$, $48 \mathrm{~h}$ and $72 \mathrm{~h}$.

For MEHP in plasma of allogenic peripheral stem cell donors, which was stored at $-80^{\circ} \mathrm{C}$, first an increase during $48 \mathrm{~h}$ and a decrease after $72 \mathrm{~h}$ was detected. Data for $0,24 \mathrm{~h}, 48 \mathrm{~h}$ and $72 \mathrm{~h}$ showed no statistical significant effect ( $p>0.05$, Student's $t$-test, Fig. 6, blue columns).

Mean values and standard deviations of MEHP concentration values in plasma from allogenic peripheral stem cell donors, which were stored at $4{ }^{\circ} \mathrm{C}$ for $72 \mathrm{~h}$ increased statistically significant ( $p<0.05$, Student's $t$-test, Fig. 6, red columns). The same effect was observed for the samples stored at $37^{\circ} \mathrm{C}$ for $72 \mathrm{~h}$ (Fig. 6, green columns). In contrast, amounts of DEHP in plasma from allogenic peripheral stem cell donors stored at $-80^{\circ} \mathrm{C}$ after $24 \mathrm{~h}, 48 \mathrm{~h}$ and $72 \mathrm{~h}$ were below the detection limit (Fig. 7).

When the plasma was stored at $4^{\circ} \mathrm{C}$, DEHP significantly increased after $24 \mathrm{~h}, 48 \mathrm{~h}$ and $72 \mathrm{~h}$ when compared to the analysis immediately before storing ( $p<0.05$, Student's $t$-test, Fig. 7 , red columns). Same results were obtained for DEHP concentrations from plasma samples which were stored at $37^{\circ} \mathrm{C}$ for $72 \mathrm{~h}$ (Fig. 7, greens columns).

As a control, analyses of DEHP and MEHP were made in $0.9 \%$ sodium chloride $(\mathrm{NaCl})$ which was stored under the same conditions as previous samples $\left(-80^{\circ} \mathrm{C}, 4^{\circ} \mathrm{C}, 37^{\circ} \mathrm{C}\right.$ for $\left.72 \mathrm{~h}\right)$. The amounts of DEHP and MEHP were below the detection limit for all time points of measurement. 


\subsection{DEHP and MEHP contamination from tube system}

Additionally, the influence of the tube system as part of the apheresis system on DEHP and MEHP concentrations was analyzed. For this purpose, the tube system was stored with the remaining donor blood for $24 \mathrm{~h}$ at room temperature. Data were recorded immediately after removing the tube system from the apheresis system and after $24 \mathrm{~h}$ of storage. During the 24 hours an increase from $0 \mu \mathrm{g} / \mathrm{ml}$ to $5.39 \mu \mathrm{g} / \mathrm{ml} \pm 5.85$ for MEHP was detected and a release of $0.22 \mu \mathrm{g} / \mathrm{ml} / \mathrm{h}$ MEHP was calculated. The DEHP increase was detected from $0 \mu \mathrm{g} / \mathrm{ml}$ to $5.84 \mu \mathrm{g} / \mathrm{ml} \pm 5.85$ within 24 hours or a calculated DEHP release of $0.22 \mu \mathrm{g} / \mathrm{ml} / \mathrm{h}$.

Mean transit times were determined from donor protocols: $2.7 \mathrm{~h} \pm 1.1$ for autologous stem cell donors and $3.2 \mathrm{~h} \pm 0.7$ for allogenic stem cell donors.

\section{Discussion}

Analyses of cellular components before and after apheresis showed that the procedure had a crucial influence on blood count. After an apheresis, significantly lower values could be detected in allogenic and autologous donor groups, because beside collected stem cells also isolated cellular components were extracted, which was also found in a study by Cherqaoui et al. (2013) [12]. Additionally, Das et al. showed in 2009 a decrease of cellular components during thrombocytes apheresis [13]. When compared, blood counts of the autologous group showed significantly lower amounts before and after apheresis in contrast to the allogenic group. This can be traced back to various hematopoietic systemic diseases which occur in the group of autologous donors and which made it necessary for them to receive an autologous stem cell apheresis $[14,15]$. Significant high numbers of leucocytes were detected for allogenic stem cell donors before and after apheresis, which might be the result of treatment with G- CSF (Granulocyte Colony Stimulating Factor) before apheresis. When determined if peripheral stem cell apheresis increased the exposure to DEHP and MEHP, it was observed that the tube system as part of the apheresis system causes a release of $0.22 \mu \mathrm{g} / \mathrm{ml} / \mathrm{h}$ for both DEHP and MEHP and results in concentrations of these phthalates which can also be found in apheresis products in autologous and allogenic stem cell donors. Significant higher concentrations for allogenic stem cell donors may be a result from significant higher transit times when apheresis was conducted for allogenic stem cell donors. Here, mean transit time was $3.2 \pm 0.7 \mathrm{~h}$ compared to $2.7 \pm 1.1 \mathrm{~h}$ for autologous stem cell donor. As a consequence the processed blood was exposed to the tube system for a longer time. Another factor that could not be investigated in this study might originate from high triglyceride concentrations found in the donors' serum. DEHP is lipid soluble and high triglyceride concentrations in the serum may promote the dissolution of DEHP and declare different plasticizer concentrations in apheresis products from the two groups [4, 5, 16-18]. In peripheral blood from allogenic donors concentrations of DEHP and MEHP were below detection limit before apheresis and were not significantly increased after apheresis. This is in contrast to the calculated DEHP-release of $0.22 \mu \mathrm{g} / \mathrm{ml} / \mathrm{h}$. Based on this higher concentrations were expected. Possible reasons might be that several plasma and liver enzymes lead to a rapid degradation of DEHP and also to lower concentrations found in the blood samples. Additionally, DEHP can accumulate in organs leading to lower concentrations in the blood [16, 19]. Autologous donors showed no detectable concentrations of MEHP, likely because of degradation of MEHP. DEHP in the peripheral blood was detectable already before apheresis and increased significantly after apheresis. Tickner et al. found in their study from 2001 that chronically sick people generally show increased DEHP concentrations.

For bone marrow preparations as well detectable concentrations of DEHP and MEHP were found. Compared to apheresis products from allogenic stem cell donors, as expected, concentrations were 
significant lower. Bone marrow aspiration from iliac crest takes in mean 2 hours and thus is shorter than peripheral stem cell apheresis. In addition, no contamination occurs with plasticizers from a tube system of the apheresis system. Detectable concentrations may derive from other instruments used for bone marrow aspiration which are made of PVC-containing phthalate mixtures, e.g. a tube system maintaining anesthesia, syringes and other materials [20-22].

Furthermore, this study could reveal information regarding influence of storage temperature and period on DEHP and MEHP concentrations in the different types of preparations. An increased storage period showed a significant increase of DEHP and MEHP [8, 19, 23, 24]. An additional influence on DEHP and MEHP concentrations is given by storage temperature. Plasma storage at $4^{\circ} \mathrm{C}, 37^{\circ} \mathrm{C}$ and $-80^{\circ} \mathrm{C}$ showed that increasing the temperature results in an expanded release of phthalates DEHP and MEHP [25]. This also can be found in literature where Cole et al. in 1981 demonstrated in their study that the enzymatic activity in plasma, which catalyzes the transformation from DEHP to MEHP, is increased at higher temperatures. Thus, a protective measure was immediate freezing of fresh plasma to avoid contamination with DEHP and MEHP $[4,8]$.

Another focus was to determine a possible difference between cellular and non-cellular components which were exposed to phthalates released from storage bags. Tickner et al. described in 2001 that blood products can dissolve lipophilic DEHP from PVC-containing material. Inoue et al. (2001) claimed that DEHP can be dissolved out of the PVC into the blood, because chemically it is not tightly bound to a PVC-polymer. Additionally they found that the highest release of DEHP from PVC-containing bags was detected in whole blood samples. The highest degree of hydrolysis, the DEHP to MEHP ratio, was found in plasma samples. They concluded, that this may be a result of different lipid compositions in whole blood and plasma [4, 19, 24]. In their study, the highest concentration of DEHP in apheresis products was observed after 72 hours in whole blood and in contrast the highest MEHP concentration was found in pure plasma. DEHP binds to cellular blood components which declares increased concentrations of DEHP in apheresis products, and that highest enzymatic activity, which transforms DEHP to MEHP, was observed in plasma [26]. The lowest DEHP/MEHP ratio was detected in pure plasma during the whole storage period. This study is in accordance with literature findings.

Another experiment in this study further revealed that pure $0.9 \%$ sodium chloride stored for $72 \mathrm{~h}$ at $4{ }^{\circ} \mathrm{C}$ did not contribute to the release of DEHP out of PVC. Over the whole storage period DEHP and MEHP levels were below detection limit. These findings affirm that DEHP is water-insoluble and its release was provoked by lipid-containing solution/substances [18, 27, 28].

Finally, this study has focuses on donor safety questions and if detected, DEHP and MEHP concentrations for peripheral stem cell apheresis and donors who received an invasive bone marrow aspiration were below TDI (tolerable daily intake). Furthermore, an evaluation of recipients was conducted in view of possible increased DEHP and MEHP concentrations caused by the apheresis product or bone marrow preparation transplantation. Varying TDI values can be found in literature: $37-48 \mu \mathrm{g} / \mathrm{kg}$ bw/day for DEHP and $37 \mu \mathrm{g} / \mathrm{kg}$ bw/day [3, 29, 30]. Depending on determined transit times of autologous and allogenic stem cell donors as well as DEHP/MEHP release out of the tube system following values were calculated: allogenic stem cell donors received estimated values for DEHP and MEHP of each $3573.9 \pm 782 \mu \mathrm{g}$ per apheresis procedure. Autologous donors received guessed values of $2988.4 \pm 1217.5 \mu \mathrm{g}$ per apheresis procedure. Mean bodyweights were $81.4 \mathrm{~kg}$ for allogenic donors and $80.3 \mathrm{~kg}$ for autologous groups. This leads to a calculated intake of $43.9 \pm 9.6 \mu \mathrm{g} / \mathrm{kg}$ bw/day for DEHP and MEHP for allogenic donors and an intake of $37.3 \pm 15.2 \mu \mathrm{g} / \mathrm{kg}$ bw/day for autologous donors. Data from this study show that the TDI for DEHP and MEHP was not exceeded for both allogenic and autologous donors who underwent a peripheral stem cell apheresis procedure and as a conclusion, donor safety can be ensured. This is in contrast to results from a study by Koch et al. (2006) where an intake of $38 \mu \mathrm{g} / \mathrm{kg}$ bw/day during thrombocytapheresis was found which exceeds TDI [31]. 
Another study summarizes a DEHP contamination of $6.5 \mu \mathrm{g} / \mathrm{kg}$ bw/day during thrombocytapheresis which falls below TDI and is in accordance with this study [16]. In addition, Sampson et al. confirm in their study that neither thrombocytapheresis nor plasma donation cause DEHP contamination for donors which exceed TDI [4].

Furthermore, here we also evaluated possible safety limitations caused by increased DEHP or MEHP concentrations for recipients of apheresis products. DEHP concentrations in a mean volume of $162 \mathrm{ml}$ apheresis product, which were stored for an average of 47 days at $-175^{\circ} \mathrm{C}$, were calculated $1145 \mu \mathrm{g} \pm 897 \mu \mathrm{g}$. Based on this, a mean intake of $3318 \mu \mathrm{g} /$ day for autologous stem cell donors is given (78 kg mean body weight). Again, this DEHP concentration is below TDI, but it has to be mentioned that potential additional DEHP, which originates from transfusion equipment in later procedures, was disregarded for this calculation. Estimated values for allogenic peripheral stem cell apheresis products (mean volume of $179 \mathrm{ml}$ ) were $100 \mu \mathrm{g} / \mathrm{ml}$ when guessed storage conditions were at $4^{\circ} \mathrm{C}$ for 24 hours (exact data not available). After a transfusion with this product a concentration of $17900 \mu \mathrm{g}$ was calculated and TDI is exceeded with an allogenic apheresis product. Similar results were found by others, where concentrations of $6.8-36.5 \mu \mathrm{g} / \mathrm{ml}$ for erythrocytes concentrate, $11.6-18.5 \mu \mathrm{g} / \mathrm{ml}$ for frozen plasma, $1.8-15 \mu \mathrm{g} / \mathrm{ml}$ for thrombocytes concentrate and $15-83.2 \mu \mathrm{g} / \mathrm{ml}$ for whole blood is mentioned [24]. For all transfusions, TDI was exceeded. Samson as well described TDI-exceeding DEHP concentrations in thrombocyte concentrates stored at $22^{\circ} \mathrm{C}$ for 7 days and erythrocytes concentrates stored at $4^{\circ} \mathrm{C}$ for 35 days [4]. Already in 1986, Rock et al. found DEHP release with concentrations of $0.25 \mathrm{mg} / 100 \mathrm{ml} /$ day out of storage bags where whole blood was stored at $4{ }^{\circ} \mathrm{C}$ leading to a theoretical contamination of $5 \mathrm{mg} / 100 \mathrm{ml}$ or $15 \mathrm{mg}$ DEHP for a whole blood storage bag and these results are similar to this study [25]. Referring to the literature, the autologous donors from peripheral stem cell apheresis did not exceed TDI with an apheresis product transfusion, because the volume was lower compared to volumes used in literature.

In summary, this study demonstrates that during peripheral stem cell apheresis procedure the phthalate DEHP dissolved out of the tube system consisting of a PVC containing phthalate mixture. Dissolution resulted in increased contamination with DEHP and its primary degradation product MEHP in donors. However, concentrations were below TDI and thereby tolerable. In view of storage conditions it could be shown that storage period has influence on DEHP and MEHP concentrations. Furthermore, release of DEHP was directly correlating with storage temperature.

It can be noted, that the risk of DEHP contamination can be minimized when apheresis products with short storage periods are chosen. Additionally, the use of phthalate free storage bags is recommended if there are no further disadvantages expected for stored substances. Considering long transit times, DEHP-free tube systems also had positive effects on donors of peripheral stem cell apheresis.

\section{References}

[1] Lyche JL, Gutleb AC, Bergman A, et al. Reproductive and developmental toxicity of phthalates. J Toxicol Environ Health B Crit Rev 2009;12:225-49.

[2] Carmen R. The selection of plastic materials for blood bags. Transfus Med Rev 1993;7:1-10.

[3] Hildenbrand SL, Lehmann HD, Wodarz R, Ziemer G, Wendel HP. PVC-plasticizer DEHP in medical products: Do thin coatings really reduce DEHP leaching into blood? Perfusion 2005;20:351-7.

[4] Sampson J, de Korte D. DEHP-plasticised PVC: Relevance to blood services. Transfus Med 2011;21:73-83.

[5] Simmchen J, Ventura R, Segura J. Progress in the removal of di-[2-ethylhexyl]-phthalate as plasticizer in blood bags. Transfus Med Rev 2012;26:27-37.

[6] Estep TN, Pedersen RA, Miller TJ, Stupar KR. Characterization of erythrocyte quality during the refrigerated storage of whole blood containing di-(2-ethylhexyl) phthalate. Blood 1984;64:1270-6.

[7] Seidl S, Gosda W, Reppucci AJ. The in vitro and in vivo evaluation of whole blood and red cell concentrates drawn on CPDA-1 and stored in a non-DEHP plasticized PVC container. Vox Sang 1991;61:8-13. 
[8] Cole RS, Tocchi M, Wye E, Villeneuve DC, Rock G. Contamination of commercial blood products by di-2-ethylhexyl phthalate and mono-2-ethylhexyl phthalate. Vox Sang 1981;40:317-22.

[9] Segura J, Ventura R, Pascual JA. Current strategic approaches for the detection of blood doping practices. Forensic Sci Int 2011;213:42-8.

[10] Solymos E, Guddat S, Geyer H, et al. Rapid determination of urinary di(2-ethylhexyl) phthalate metabolites based on liquid chromatography/tandem mass spectrometry as a marker for blood transfusion in sports drug testing. Anal Bioanal Chem 2011;401:517-28.

[11] Herr C, zur Nieden A, Koch HM, et al. Urinary di(2-ethylhexyl)phthalate (DEHP)-metabolites and male human markers of reproductive function. Int J Hyg Environ Health 2009;212:648-53.

[12] Cherqaoui B, Rouel N, Auvrignon A, et al. Peripheral blood stem cell collection in low-weight children: Retrospective comparison of two apheresis devices. Transfusion 2014;54:1371-8.

[13] Das SS, Chaudhary R, Verma SK, Ojha S, Khetan D. Pre- and post- donation haematological values in healthy donors undergoing plateletpheresis with five different systems. Blood Transfus 2009;7:188-92.

[14] Link H, Kolb HJ, Ebell W, et al. Transplantation of hematopoietic stem cells. II: Indications for transplantation of hematopoietic stem cells after myeloablative therapy. Med Klin (Munich) 1997;92:534-45.

[15] Link H, Kolb HJ, Ebell W, et al. Transplantation of hematopoietic stem cells. I: Definitions, principle indications, complications. Med Klin (Munich) 1997;92:480-91, 505.

[16] Buchta C, Bittner C, Hocker P, et al. Donor exposure to the plasticizer di(2-ethylhexyl)phthalate during plateletpheresis. Transfusion 2003;43:1115-20.

[17] Fay M, Donohue JM, De Rosa C. ATSDR evaluation of health effects of chemicals. VI. Di(2-ethylhexyl)phthalate. Agency for Toxic Substances and Disease Registry. Toxicol Ind Health 1999;15:651-746.

[18] Myhre BA. Toxicological quandary of the use of bis (2-diethylhexyl) phthalate (DEHP) as a plasticizer for blood bags. Ann Clin Lab Sci 1988;18:131-40.

[19] Tickner JA, Schettler T, Guidotti T, McCally M, Rossi M. Health risks posed by use of Di-2-ethylhexyl phthalate (DEHP) in PVC medical devices: A critical review. Am J Ind Med 2001;39:100-11.

[20] Pulsipher MA, Chitphakdithai P, Logan BR, et al. Acute toxicities of unrelated bone marrow versus peripheral blood stem cell donation: Results of a prospective trial from the National Marrow Donor Program. Blood 2013;121:197-206.

[21] Doull J, Cattley R, Elcombe C, et al. A cancer risk assessment of di(2-ethylhexyl)phthalate: Application of the new U.S. EPA Risk Assessment Guidelines. Regul Toxicol Pharmacol 1999;29:327-57.

[22] Lovekamp-Swan T, Davis BJ. Mechanisms of phthalate ester toxicity in the female reproductive system. Environ Health Perspect 2003;111:139-45.

[23] Sjoberg PO, Bondesson UG, Sedin EG, Gustafsson JP. Exposure of newborn infants to plasticizers. Plasma levels of di-(2-ethylhexyl) phthalate and mono-(2-ethylhexyl) phthalate during exchange transfusion. Transfusion 1985;25:424-8.

[24] Inoue K, Kawaguchi M, Yamanaka R, et al. Evaluation and analysis of exposure levels of di(2-ethylhexyl) phthalate from blood bags. Clin Chim Acta 2005;358:159-66.

[25] Rock G, Labow RS, Tocchi M. Distribution of di(2-ethylhexyl) phthalate and products in blood and blood components. Environ Health Perspect 1986;65:309-16.

[26] Labow RS, Card RT, Rock G. The effect of the plasticizer di(2-ethylhexyl)phthalate on red cell deformability. Blood 1987;70:319-23.

[27] Posnack NG, Lee NH, Brown R, Sarvazyan N. Gene expression profiling of DEHP-treated cardiomyocytes reveals potential causes of phthalate arrhythmogenicity. Toxicology 2011;279:54-64.

[28] Rubin RJ, Ness PM. What price progress? An update on vinyl plastic bags. Transfusion 1989;29:358-61.

[29] Koch HM, Drexler H, Angerer J. An estimation of the daily intake of di(2-ethylhexyl)phthalate (DEHP) and other phthalates in the general population. Int J Hyg Environ Health 2003;206:77-83.

[30] Koch HM, Rossbach B, Drexler H, Angerer J. Internal exposure of the general population to DEHP and other phthalatesdetermination of secondary and primary phthalate monoester metabolites in urine. Environ Res 2003;93:177-85.

[31] Koch HM, Preuss R, Angerer J. Di(2-ethylhexyl)phthalate (DEHP): Human metabolism and internal exposure-an update and latest results. Int J Androl 2006;29:155-65; discussion 81-5. 